\title{
Psychiatry, the law and death on the roads
}

\author{
Harvey Gordon
}

Abstract The motor vehicle on the road has a history of only just over 100 years. It is a major form of personal and public transport, but is also associated with hazards and risks. Many more people are killed on the roads each year in Britain than are the victims of homicide. General and forensic pyschiatric evaluation of offenders charged with or convicted of motoring offences is, however, infrequent, despite the presence of mental health problems in some of them. I describe psychiatric, criminological and legal factors associated with driving of motor vehicles, as many psychiatric patients have driving licences and have access to a vehicle or, indeed, may decide to drive unlicensed.

The benefits of road travel are so extensive that it has become a crucial part of modern life. Yet its efficiency is limited by traffic congestion, and there are considerable risks to health and life from traffic accidents and environmental pollution. Such dangers are not new. St Paul refers to the hazards of travel in the New Testament (2 Corinthinians 11.26). In England and Wales in the 1860s, the rate of deaths on the roads per million of the male population was about $60 \%$ of that recorded a century later, but the death rate on all main forms of transport (railway, road and canal) was almost twice as high in the 1860s than in the 1960s (Leeming, 1969). Motor vehicles are essentially an innovation of the 20th century (Thorold, 2003). The first fatal road traffic accident in Britain involving a motorised vehicle occurred in 1896 (Norman, 1962). The number of fatalities on the roads in the UK peaked in the mid1960s, at about 8000. There followed a drop due to the introduction of the speed limit, more stringent laws on drink-driving and seat-belt legislation (Harris, 2000), such that by the year 2000 about 4000 people died in road traffic accidents (Department for Transport, 2003). By the late 1980s, however, death on the road due to reckless driving was the most common type of homicide, with numbers greater than those recorded as murder and manslaughter (Gunn \& Taylor, 1993).

\section{Mental disorder and road traffic accidents}

Most road traffic accidents are caused by human error (Cremona, 1986) with additional factors, including the road conditions, climate and the road-worthiness of the vehicle. Driving behaviour is highly complex and human error may comprise unintended actions as well as deliberate violation of traffic law (Reason et al, 1990). Medical conditions of drivers, with the exception of disorders related to alcohol, account for less than $1 \%$ of road traffic accidents in which injury is involved (Raffle, 1985).

Earlier studies indicated that those with psychotic illnesses showed up to twice the rate of road traffic accidents than did a control group (Waller, 1965). More recent reviews have revealed no excess (Armstrong \& Whitlock, 1980; Silverstone, 1988). The level of risk to others may be raised where the content of delusions or hallucinations incorporates other road users (Driver and Vehicle Licensing Agency, 2001), although the degree of increase has not been quantified. Where psychotic symptoms are active, risk is probably higher and drivers are usually safer when stabilised on psychotropic medication (Harris, 2000). These findings are consistent with the general notion that there is a modest elevated risk associated with schizophrenia when active symptoms are present.

In the case of bipolar affective disorder, it is intuitive that patients in a hypomanic episode may drive rapidly (Cremona, 1986), but supporting evidence is unavailable (Silverstone, 1988). Patients in a depressed episode with psychomotor retardation may show impaired concentration (Cremona, 1986) and increased suicidality while driving (Isherwood et al, 1982; Silverstone, 1988).

Various studies have shown an increased accident rate for drivers with dementia (Kolowski \& Rossiter, 2000), borderline cognitive impairment (Marottoli et al, 1994) and neurological impairment (McKenna, 1998).

Harvey Gordon is a consultant forensic psychiatrist at Littlemore Mental Health Centre (Sandford Road, Littlemore, Oxon OX4 4XN, UK. E-mail: Harvey.gordon@oxmhc-tr.nhs.uk) and an honorary senior lecturer in forensic psychiatry at the University of Oxford. He has also worked at Broadmoor Hospital and at the Maudsley and Bethlem Royal Hospitals. 
Alcohol consumption has long been identified as one of the most important factors in road traffic accidents (Shinar, 1978; Del Rio et al, 2001). Bierness (1993) found that alcohol interacted with underlying personality factors such as hostility and aggression, rendering some drivers more vulnerable to road traffic accidents. An 'antisocial lifestyle' comprises a range of related behaviours, including violent and non-violent offences, substance misuse, sexual promiscuity and reckless driving (Carter, 2003). Early age of onset of drink-driving has been found to be associated with mental illness and violent criminality (Rasanen et al, 1999). Those convicted of drink-driving have been found to be more likely also to misuse alcohol or be alcohol dependent, as well as to have comorbid disorders such as misuse of other drugs, depressive illness and post-traumatic stress disorder (Lapham et al, 2001).

The 1990s in Britain saw an increase in the number of fatal road traffic accidents caused by drivers under the influence of drugs other than alcohol. Cannabis was the drug most frequently found in the bloodstream. The presence of drugs was highest among fatalities who had been unemployed, and it was associated with male drivers under 40 years of age and female drivers over 40; the females were more likely to have been driving under the influence of prescribed drugs rather than drugs of misuse (Tunbridge et al, 2001). People taking anxiolytics and hypnotics are known to be at heightened risk of road traffic accidents (Barbone $e t$ $a l, 1998)$. The risk of being involved in an accident may also be elevated in people who have been affected by adverse life events such as recent separation or divorce (McMurray, 1970).

\section{Road rage}

A much quoted study is that by Tillman \& Hobbs (1949), which found that a 'high-accident' group of taxi drivers showed marked intolerance of and aggression towards authority. These drivers manifested elements of conduct disorder, psychological maladjustment and an irresponsible approach to driving and were more likely to have a record of criminal convictions. Other early studies confirmed that a car can be used by those so disposed as a means of expressing aggression (Whitlock, 1971). The term road rage, although coined only in the late 1980s, is not therefore a new phenomenon. Fong et al (2001), in a British study based in inner London, found that $53 \%$ of drivers surveyed had been victims of road rage in the preceding 12 months considerably less than the figure of $90 \%$ found by the Automobile Association in the mid-1990s (Joint, 1995). Men tend to commit dangerous traffic
Box 1 The likely profile of a road-rage driver

- Male

- Young: teenage or early 20s

- Single

- Unemployed or in low-status employment

- A history of substance misuse, aggressive behaviour and criminality

- Little driving experience

violations and behave aggressively on the roads more frequently than women (Aberg \& Rimmo, 1998), and younger, less experienced drivers have the highest risk of involvement in fatal crashes (Moffatt, 2002). Many road-rage incidents are limited to an angry expression or altercation, but some result in serious violence, sometimes fatal, especially in the USA, where the driver may have a gun in the car (Miller et al, 2002). No figures are available for the number of serious injuries or fatalities from episodes of road rage in Britain.

Although the immediate trigger for a road-rage incident may occur during driving, the driver may already be aroused before getting into the car. For example, a Manchester man, enraged after seeing his football team defeated, lost control of his car while driving dangerously, killing both himself and his 12-year-old son (Britten, 2003). Fong et al (2001) found that road rage was associated with higher levels of aggression as well as with a history of substance misuse and abnormal personality traits. Hennessy \& Wiesenthal (2002) add the personality variable of vengefulness as a factor in serious violence on the road. Revenge is generally much understudied and underplayed as a component in violence, and is perhaps the most primitive and basic impulse of all. Aggressive driving behaviour is a complex phenomenon with a range of psychological causes (Lajunen \& Parker, 2001). It is also a cross-cultural problem, occurring in many different countries (Parker et al, 2002). Box 1 shows the likely profile of a road-rage driver.

\section{Car crime}

As property offences constitute the most common type of criminality (Gunn \& Taylor, 1993), the theft of a car or of property from a vehicle is a most common form of theft (Corbett, 2003). About 400000 cars per year were stolen in Britain in the late 1990s (Knowles, 2003). Thefts of cars may be either temporary, for the purpose of joyriding, or permanent, in which case professional car thieves are usually involved. Drivers of stolen cars are more likely to be involved in a car crash (Knowles, 2003). 
Car theft is often the precursor to a criminal career, beginning usually in the mid-teenage years, but occasionally as early as 10 years of age (Corbett, 2003). No figures are available for the frequency of car theft by patients with mental disorders.

Another common car crime is driving without a valid driving licence, which is also associated with other forms of traffic offending and raised crash risk (de Young et al, 1997). Driving without motor insurance is also a crime. As people are required to disclose their medical history in applying for insurance and some insurance companies refuse to insure drivers with mental disorders, some may well be driving without insurance (Brown, 1993).

The early paper by Tillmann \& Hobbs (1949) pointed to an association between risky driving and an underlying propensity towards antisocial behaviour. Subsequent studies have tended to reach similar conclusions (Mayer \& Treat, 1977). The criminal histories of certain types of traffic offender are very similar to those of mainstream criminal offenders, especially in the case of drivers who have been disqualified and, to a lesser extent, of those convicted of dangerous driving (Rose, 2000).

Finally, it is worth noting that a car may be used in the commission of crimes such as burglary, rape, drive-by shooting and terrorist attack (car bombing). The use of a motor vehicle as a weapon or facilitator of crime has to date been overlooked in forensic psychiatric studies of mentally disordered offenders.

\section{Suicide and homicide on the roads}

Psychoanalytic perspectives may have influenced earlier studies that postulated unconscious selfdestructive impulses, sometimes together with alcohol misuse, as underlying causes of some fatal automobile accidents (Selzer \& Payne, 1962). A study in Finland reported that $2.6 \%$ of all driver fatalities had been officially classified as suicides, whereas the probable true figure was $5.9 \%$ (Ohberg et al, 1997). This estimate was higher than the $2.7 \%$ published in an earlier British study (Jenkins \& Sainsbury, 1980), which examined the claim that single-vehicle accidents are a reflection of suicidality. However, not all studies of 'driver suicides' have shown a history of suicidal ideation, suggesting that many may be impulsive acts in response to acute distress rather than well-established suicidality. The literature on the use of motor vehicles in suicide has tended to focus on asphyxiation by car exhaust gas rather than death by deliberately dangerous driving (Cantor, 2000).

Suicide by dangerous driving raises the risks not only to the driver but also to any passengers,
Table 1 Psychiatric disorders in people who crashed their cars with suicidal $(n=30)$, homicidal $(n=3)$ or combined suicidal and homicidal $(n=7)$ intent

$$
\text { Drivers }(n=40)
$$

$\begin{array}{lcc}\text { Psychiatric disorder } & n & \% \\ \begin{array}{l}\text { Hysterical, } \\ \text { passive-aggressive or }\end{array} & 34 & 75 \\ \text { sociopathic personality } & & \\ \text { Psychosis } & 6 & 15 \\ \text { Schizophrenia } & 4 & 10 \\ \text { Schizoaffective psychosis } & 1 & 2.5 \\ \text { Depressive illness } & 1 & 2.5\end{array}$

Data source: MacDonald (1964).

pedestrians and people in other vehicles. In Ohberg et al's study (1997), in almost $4 \%$ of 'suicide crashes', someone other than the driver was killed. MacDonald (1964) stated that death by automobile offered special opportunity for concealment of suicide and homicide, and he found that homicidal impulses were relevant in the genesis of the suicide in several cases. Ohberg et al (1997) found several factors that were common to many driver suicides: the drivers were young men driving alone, the accident was a head-on collision with another vehicle of much heavier weight, the driver had experienced stressful life events and had a mental disorder, including long-term alcohol misuse.

As yet there is no full forensic psychiatric profile of individuals who drive dangerously with the intention of killing themselves. None of the studies of suicide by motor vehicle has included the drivers' criminal record or history of antisocial behaviour. However, MacDonald's 1964 study of suicide and homicide by motor vehicle carried out in Colorado, USA, did report on the mental state of the drivers (MacDonald, 1964). The results of this part of the study are summarised in Table 1 . As an example, Macdonald's article noted the case of a 32-year-old woman with schizophrenia who, while driving with her husband and five children, deliberately crashed into the rear of another car at 80 miles per hour, apparently because voices had told her to do it so that the family could all be born again. I also know of patients convicted of manslaughter using the motor vehicle as a weapon who have been diagnosed with schizophrenia and admitted to high-security hospitals or medium secure units. Suicide by drivers may allow for self-destructive urges to be enacted in a violent manner, enabling the concomitant discharge of uncontainable anger.

Not all vehicle accidents are caused by the driver. In some cases, conscious or unconscious suicidal and/or homicidal ideation may be manifested by a pedestrian stepping into the path of moving traffic. 
Table 2 History of motor vehicle legislation

\begin{tabular}{|c|c|c|}
\hline Year & Legislation & Details \\
\hline 1835 & Highway Act & Created the offence of driving any carriage on a pavement \\
\hline 1847 & Town Police Clauses Act & Created the offence of furious driving of any horse or carriage \\
\hline 1861 & Offences Against Persons Act & $\begin{array}{l}\text { Created the offence of causing bodily harm by wanton or furious } \\
\text { driving of a carriage or vehicle }\end{array}$ \\
\hline 1903 & Motor Car Act & $\begin{array}{l}\text { Introduced the registration of motor vehicles by number plates, } \\
\text { disqualification from driving, the requirement to stop after a road } \\
\text { traffic accident, a speed limit of } 20 \text { miles per hour and the new } \\
\text { offence of reckless driving }\end{array}$ \\
\hline 1930 & Road Traffic Act & $\begin{array}{l}\text { Introduced the offences of careless driving and of being unfit to } \\
\text { drive owing to drink or drugs }\end{array}$ \\
\hline 1934 & Road Traffic Act & $\begin{array}{l}\text { Introduced an urban speed limit of } 30 \text { miles per hour and the } \\
\text { mandatory driving tests }\end{array}$ \\
\hline 1956 & Road Traffic Act & $\begin{array}{l}\text { Introduced the offence of causing death by reckless or dangerous } \\
\text { driving (subsequently amended by the Road Traffic Act } 1972 \text { and } \\
\text { the Criminal Law Act 1977) }\end{array}$ \\
\hline 1985 & Road Traffic Law Review & $\begin{array}{l}\text { The North Report (Department for Transport \& Home Office (1988) } \\
\text { reviewed a range of driving offences, resulting in the Road Traffic } \\
\text { Act 1988, which was amended in } 1991\end{array}$ \\
\hline 1988 & Road Traffic Act & The Road Traffice Acts of 1988 and 1991 introduced clearer \\
\hline 1991 & Road Traffic Act & $\begin{array}{l}\text { definitions of dangerous driving focusing on the standard of } \\
\text { driving, rather than on the intent of the driver }\end{array}$ \\
\hline 2000 & Traffic Penalty Review & $\begin{array}{l}\text { This consultation paper (Home Office, 2000) placed increased } \\
\text { emphasis on longer sentences for dangerous driving }\end{array}$ \\
\hline
\end{tabular}

However, most fatally injured pedestrians in urban areas are children and elderly people, and it is unlikely that many of these would be seeking suicide under the wheels of a car (Corbett, 2003).

\section{Dangerous driving and the law}

Legislation regarding driving can be traced back to the Romans, who introduced laws to try to reduce the number of collisions between drunken charioteers (Whitlock, 1971). Motor vehicle traffic law in Britain initially reflected the problems resulting from the need for potentially nervous horse-drawn transport to share the road with the noisy motor car. It was later influenced by debates as to whether cars are inherently dangerous or whether the danger arises from the ferocity of those who drive them (Forbes, 1972).

Table 2 shows the evolution of UK road traffic legislation since the early 1800 s. Throughout the 20th century, popular opinion seemed to reflect the view that the driving offender, however dangerous, was not seen as a 'criminal' (Fitzgerald, 1969), and sentences were more lenient even if people were killed. Recently, however, the Traffic Penalty Review (Home Office, 2000) has resulted in an increase in the length of sentences for more dangerous driving offences. The main offences related to dangerous driving that are covered by the Road Traffic Act 1991 are shown in Table 3.

In practice, there are various dilemmas in reaching the appropriate charge and conviction for driving offences. Numerous instances of careless or dangerous driving go unprosecuted in the absence of ensuing collision or injury. There is no consensus on whether speeding itself should constitute dangerous driving. When a death is caused by dangerous driving, the victim's family or friends often feel that the sentence of the driver is too lenient and an insufficient response to the loss of life.

Occasionally, it can be shown that a driver deliberately caused the death of one or more victims, in which case a charge of murder or manslaughter may be possible. In most cases, there is no intent to harm or kill and what we are seeing is a driver's irresponsibility, carelessness and, at times, lack of concern for the welfare of others. Some road traffic accidents are caused by temporary driver distraction, including the effects of fatigue. Whether or not a death occurs may be arbitrary and it has been argued that the law should reflect the commission of dangerous driving, rather than its outcome or consequences. However, the sanctity 
Table 3 The four main offences related to driving (Road Traffic Act 1991)

Offence

Dangerous driving

Causing death by dangerous driving

Careless and inconsiderate driving

Causing death by careless driving when under the influence of drink or drugs

\section{Conditions}

A driver is regarded as guilty of dangerous driving if (a) the way he or she drives falls far below what would be expected of a competent and careful driver and (b) it would be obvious to a competent and careful driver that driving in that way would be dangerous

It must be shown that the individual's driving fell below standard because he or she was not displaying the care and attention that might be expected of a competent driver or that other road users were inconvenienced by the inconsiderate driving of human life is such that most legislations do have separate offences reflecting whether or not a death has occurred. Some have argued that victims of road traffic accidents who have sustained serious, chronically incapacitating injuries are also not adequately justly dealt with by current legislation, injury from a road traffic accident being regarded as one of the most common precipitants of posttraumatic stress disorder. Ultimately, it is for the court to determine the culpability of a driving offender, taking account of the level of intent, compliance with traffic law, including drink- or drug-driving, whether the required standard of driving was evident and whether or not a death has occurred. Where mental disorder is present it is necessary for a psychiatrist to evaluate its nature and to what extent it may have affected the driving, taking account of life events, mood, cognition, psychosis, personality factors and the effects of medication and treatment. Readers are referred for further information on the law in regard to dangerous driving to Smith (2002) and to the Department for Transport (2003).

\section{Concluding remarks}

On a global level, death and injury from road traffic accidents are major parameters of public risk and ill-health (Pless, 2004). In Britain, although the number of fatalities on the roads has reduced to about $50 \%$ of the level 40 years ago, road deaths are some five or six times more common than deaths by murder and manslaughter. Considerable potential exists for prevention of such mortality and associated morbidity, and the World Health Organization has declared road safety to be its focus for 2004 (World Health Organization \& World Bank, 2004).
Although almost every driver is at some time involved in a minor road accident, it is emerging that those involved in more serious crashes are very likely to be either mainstream criminal offenders or ordinary people (with no mental disorder or significant criminal record) who just drive dangerously.

Psychiatrists and related mental health professionals meet many patients who can drive. Some of these individuals will be at risk of killing or injuring themselves or others while behind the wheel, intentionally or through carelessness or recklessness. By paying greater attention to patients' use of motor vehicles and their attitudes to them, mental health professionals might contribute to the prevention of injuries and deaths. It might even be appropriate to warn certain patients of the risks that they present. Psychiatrists must also be aware that an individual accused of a crime related to driving might have acted under the influence of a mental disorder.

The car undoubtedly provides numerous benefits in modern society, but psychiatric prevention of its misuse as a weapon is in need of further research.

\section{References}

Aberg, L. \& Rimmo, P. A. (1998) Dimensions of aberrant driver behaviour. Ergonomics, 41, 39-56.

Armstrong, J. L. \& Whitlock, F. A. (1980) Mental illness and road traffic accidents. Australian and New Zealand Journal of Psychiatry, 14, 53-60.

Barbone, F., McMahon, A. D., Davey, P. G., et al (1998) Association of road traffic accidents with benzodiazepine use. Lancet, 352, 1331-1336.

Bierness, D. J. (1993) Do we really drive as we live? The role of personality factors in road crashes. Alcohol, Drugs and Driving, 9, 129-143.

Britten, N. (2003) Father and son killed by 'lunatic' driver enraged after seeing United lose. Daily Telegraph, 10th May, p. 13.

Brown, P. (1993) Mental illness and motor insurance. Psychiatric Bulletin, 17, 620-621. 
Cantor, C. H. (2000) Suicide in the Western World. In The International Handbook of Suicide and Attempted Suicide (eds K. Hawton \& K. Van Heeringen), pp. 9-28. Chichester: John Wiley \& Sons.

Carter, D. (2003) The impact of antisocial lifestyle on health $B M J, 326,834-835$.

Corbett, C. (2003) Car Crime. Cullompton: Willan Publishing

Cremona, A. (1986) Mad drivers: psychiatric illness and driving performance. British Journal of Hospital Medicine 35, 193-195

Del Rio, M. C., Gonzalez-Luque, J. C. \& Alvarez, F. J. (2001) Alcohol-related problems and fitness to drive. Alcohol and Alcoholism, 36, 256-261.

Department for Transport (2002) Road Safety Research Report No. 26, Dangerous Driving and the Law. London: Department for Transport.

Department for Transport \& Home Office (1988) Road Traffic Law Review Report. London: HMSO.

de Young, D., Peck, R. \& Helander, C. (1997) Estimating the exposure and fatal crash rates of suspended/revoked and unlicensed drivers in California. Accident Analysis and Prevention, 29, 17-23.

Driver and Vehicle Licensing Agency (2001) For Medical Practitioners: At a Glance Guide to the Current Medical Standards of Fitness to Drive. Swansea: DVLA.

Fitzgerald, P. J. (1969) Road traffic law as the lawyer sees it. In Road Accidents: Prevent or Punish (ed. J. J. Leeming), pp. 157-175. London: Cassell.

Fong, G., Frost, D. \& Stansfeld, S. (2001) Road rage: a psychiatric phenomenon? Social Psychiatry and Psychiatric Epidemiology, 36, 277- 286.

Forbes, T. W. (1972) Human Factors in Highway Traffic Safety Research. London: John Wiley \& Sons.

Gunn, J. \& Taylor, P. J. (1993) Forensic Psychiatry: Clinical Legal and Ethical Issues. Oxford: Butterworth-Heinemann.

Harris, M. (2000) Psychiatric conditions with relevance to fitness to drive. Advances in Psychiatric Treatment, 6, 261269.

Hennessy, D. A. \& Wiesenthal, D. L. (2002) Aggression, violence and vengeance among male and female drivers. Transportation Quarterly, 56, 65-75.

Home Office (2000) Road Traffic Penalties: A Consultation Paper. London: Home Office.

Isherwood, J., Adam, K. S. \& Hornblow, A. R. (1982) Life event stress, psychosocial factors, suicide attempt and auto-accident proclivity. Journal of Psychosomatic Research, 26, 371-383.

Jenkins, J. \& Sainsbury, P. (1980) Single-car road deaths disguised suicides? BMJ, 281, 1041.

Joint, M. (1995) Road Rage. London: Automobile Association.

Knowles, J. (2003) Accident Involvement of Stolen Cars in 1997 and 1998. TRL Report 577. Crowthorne: Transport Research Laboratory

Kolowski, S. J. \& Rossiter, J. (2000) Driving in Somerset. Psychiatric Bulletin, 24, 304-306.

Lajunen, T. \& Parker, D. (2001) Are aggressive people aggressive drivers? A study of the relationship between self-reported general aggressiveness, driver anger and aggressive driving. Accident Analysis and Prevention, 33, 243-255.

Lapham, S. C., Smith, E., C'de Baca, J., et al (2001) Prevalence of psychiatric disorders among persons convicted of driving while impaired. Archives of General Psychiatry, 58, 943949.

Leeming, J. J. (1969) Road Accidents: Prevent or Punish. London: Cassell.

MacDonald, J. M. (1964) Suicide and homicide by automobile. American Journal of Psychiatry, 121, 366370 .

Marottoli, R. A., Cooney, L. M., Wagner, R., et al (1994) Predictors of automobile crashes and moving violations among elderly drivers. Annals of Internal Medicine, 121, $842-846$

Mayer, R. E. \& Treat, J. R. (1977) Psychological, social and cognitive characteristics of high risk drivers: a pilot study. Accident Analysis and Prevention, 9, 1-8.
McKenna, P. (1998) Fitness to drive: A neuropsychological perspective. Journal of Mental Health, 7, 9-18.

McMurray, L. (1970) Emotional stress and driving performance: The effects of divorce. Behavioural Research in Highway Safety, 1, 100-114.

Miller, M., Azrael, D., Hennenway, D., et al (2002) Road rage in Arizona: armed and dangerous. Accident Analysis and Prevention, 34, 807-814.

Moffatt, G. K. (2002) A Violent Heart: Understanding Aggressive Individuals. London: Praeger.

Norman, L. G. (1962) Road Traffic Accidents, Epidemiology, Control and Prevention. Public Health Paper no. 12. Geneva: World Health Organization.

Ohberg, A., Penttila, A. \& Lonngvist, J. (1997) Driver suicides. British Journal of Psychiatry, 171, 468-472.

Parker, D., Lajunen, T. \& Summala, H. (2002) Anger and aggression among drivers in three European countries. Accident Analysis and Prevention, 34, 229-235.

Pless, B. (2004) Road traffic injury prevention: WHO report advocates input from public health and a systems approach (editorial). BMJ, 328, 846.

Raffle, P. A. B. (1985) Medical Aspects of Fitness to Drive: A Guide for Medical Practitioners (4th edn). London: Medical Commission on Accident Prevention.

Rasanen, P., Hakko, H. \& Jarvelin, M. R. (1999) Early-onset drunk driving, violent criminality and mental disorders. Lancet, 354, 1788.

Reason, J., Manstead, A., Stradling, S., et al (1990) Errors and violations on the roads: a real distinction? Ergonomics, 33, 1315-1332.

Rose, G. (2000) The Criminal Histories of Serious Traffic Offenders. Home Office Research Study 206. London: Home Office.

Selzer, M. L. \& Payne, C. E. (1962) Automobile accidents, suicide and unconscious motivation. American Journal of Psychiatry, 119, 237-240.

Shinar, D. (1978) Psychology on the Road: The Human Factor in Traffic Safety. Chichester: John Wiley \& Sons.

Silverstone, T. (1988) The influence of psychiatric disease and its treatment in driving performance. International Clinical Psychopharmacology, 3 (suppl. 1), 59-66.

Smith, J. C. (2002) Smith \& Hogan Criminal Law (10th edn). London: Butterworths / LexisNexis.

Thorold, P. (2003) The Motoring Age: The Automobile and Britain 1896-1939. London: Profile Books.

Tillmann, W. A. \& Hobbs, G. E. (1949) The accident-prone automobile driver. American Journal of Psychiatry, 106, 321331

Tunbridge, R. J., Keigan, M. \& James, F. J. (2001) The Incidence of Drugs and Alcohol in Road Accident Fatalities. TRL Report 495. Crowthorne: Transport Research Laboratory.

Waller, J. A. (1965) Chronic medical conditions and traffic safety. New England Journal of Medicine, 273, 1413-1420.

Whitlock, F. A. (1971) Death on the Road: A Study in Social Violence. London: Tavistock Publications.

World Health Organization \& World Bank (2004) World Report on Road Traffic Injury Prevention. Geneva: WHO.

\section{MCQs}

1 Motorised vehicles have been available since approximately:

a 1800

b 1900

c 1700

d 1820

e 1650 .

2 Mental disorder and road traffic accidents may be elevated in cases of:

a active psychosis

b well-controlled psychosis 
c hypomania

d conduct disorder

e neurological impairment.

3 Driver suicides:

a are the most common method of suicide

b account for more than $10 \%$ of all driver fatalities

c are sometimes associated with homicidal ideation

d can always be associated with well-established suicidality

e are more common in women than in men.

4 As regards car crime:

a thefts of cars are uncommon

b road traffic accidents are more commonly caused by drivers in stolen cars c driving without insurance is not illegal

d car crime may be associated with a criminal lifestyle

e cars may be used in a range of crimes.

5 As regards the law and dangerous driving:

a causing death by dangerous driving is legally regarded as murder

b most cases of risky driving result in prosecution

c recently, penalties for dangerous driving have been reduced

d the 1991 Road Traffic Act places more emphasis on the mental state of the driver than on the standard of driving

e psychiatrists have no role to play in prevention of road traffic accidents caused by their patients.

\section{Schizophrenia: full national clinical guideline on core interventions in primary and secondary care
By the National Collaborating Centre for Mental Health}

The first evidence-based clinical guideline endorsed by NICE (National Institute for Clinical Excellence) presents guidance on pharmacological, psychological and service-level interventions for schizophrenia.

In this volume, we present the complete guideline, including the evidence on which the guideline statements are based, and a detailed explanation of the methodology behind the guideline's preparation. An essential resource for all professionals involved in the management of schizophrenia, this book is a milestone in the development of truly independent and transparent clinical guidance and an essential tool in improving the quality of mental health care in the UK.

- Includes a data CD compiling all the metaanalytical data, presented both in tabular format and as Forest plots linked to each guideline statement.

- Includes a training CD to help you understand and use the guideline and interpret the data behind the guideline statements.

2003, 264pp + 2 free CD-ROMs, A4, ISBN 190124297 8, Price $£ 50.00$

AVAILABLE FROM:

Book Sales, Royal College of Psychiatrists, 17 Belgrave Square, London SW 1X 8PG, UK. Tel: + 44 (0)207235 2351 ext 146. Fax: + 44 (0)20 7245 1231. Website: www.rcpsych.ac.uk 